\title{
A ATUAÇÃO DO PSICÓLOGO COM ADOLESCENTES INFRATORES EM MEDIDA SOCIOEDUCATIVAS
}

DOI: $10.22289 / 2446-922 X$.V2EEA1

\author{
Gilbert Romer Soares $^{9}$ \\ Delza Ferreira Mendes
}

\section{RESUMO}

A adolescência é um período de transição entre a infância e a vida adulta e alguns fatores de risco e proteção podem influenciar no desenvolvimento da vida social do adolescente de forma favorável ou desfavorável. A presente pesquisa teve como objetivo discutir o papel do psicólogo nas medidas socioeducativas aplicadas a adolescentes em conflito com a lei, sendo realizada por meio de revisão da literatura. Evidenciou-se que são diversos os fatores associados ao comportamento inadequados no convívio com a sociedade. Entre eles podese destacar como fatores de risco: a carência de afinidades afetuosas puras e contribuição familiar, a influência do grupo, a agressão doméstica, antecedentes familiares, dependentes químicos e baixa autoestima, a falta de incentivo para os estudos, o desempenho escolar insuficiente, o desejo de ser livre conjugado com o empenho de buscar a efetivação do crescimento pessoal, a procura de inovação a qualquer custo e o espírito de aventura, a rebeldia. $\mathrm{O}$ estudo mostrou que ainda necessitam de aprofundamento as explicações sobre os fatores protetores que possam esclarecer os motivos que desencadeiam o envolvimento de jovens que fazem parte desse grupo de risco. A psicologia contribui no desenvolvimento de programas de medidas socioeducativas, produzindo intervenções através de compromissos ético-político, garantindo ao adolescente direitos juntamente com outros profissionais.

Palavras-Chave: Adolescente; Medida socioeducativa; Psicólogo.

\begin{abstract}
Adolescence is a period of transition between childhood and adulthood and some risk and protective factors can influence the development of adolescent social life favorably or unfavorably. This research aimed to discuss the role of psychologists in educational measures applied to adolescents in conflict with the law, being carried out through literature review. It is evident that there are several factors associated with inappropriate behavior in interaction with society. Among them may be noted as risk factors: the lack of pure loving affinities and family contribution, the group's influence, domestic assault, family history, drug addicts and low selfesteem, lack of incentive for studies, school performance insufficient, the desire to be free in conjunction with the commitment to seek the realization of personal growth, the demand for innovation at any cost and the spirit of adventure, rebellion. The study showed that still need to deepen the explanations of the protective factors that may clarify the reasons that trigger the involvement of young people who are part of this risk group. Psychology helps in the development of educational measures programs, producing interventions through ethical and political commitments, ensuring adolescent rights along with other professionals.
\end{abstract}

Keywords: Teenager; Socio-educational measures; Psychologist.

${ }^{9}$ Endereço eletrônico de contato: gilbert2009123@hotmail.com

Outubro, 2016:2(Edição Especial):117-137 


\section{INTRODUÇÃO}

A crescente violência no Brasil e no mundo, cada vez mais é percebida a participação de adolescentes nesse contexto de acentuada violência. A adolescência é uma fase no desenvolvimento humano conturbado para o mundo jovem, no qual o adolescente busca uma autoafirmação pessoal, passando por vários questionamentos e transtornos próprios desse momento de sua vida, vivenciando muitos conflitos internos, de personalidade, as mudanças hormonais. Diante dessa realidade a população se mostra cada vez mais assustada e aprisionada em suas residências, aparentemente protegidas de pessoas perigosas em sua volta.

Estudos sobre adolescentes que cometem atos infracionais apontam jovens oriundos de famílias carentes da figura paterna, problemática atual que sinaliza a ausência de um cuidador que exerça o papel de autoridade, lacunas acarretadas em decorrência da saída de casa da mãe para entrada no mercado de trabalho e afastamento da família, já que tende assumir os vários papéis de mãe cuidadora - de autoridade, etc. assim confundindo a cabeça desses que passa não ter referência. Assim, se o adolescente em desenvolvimento não tem condições de contar com o papel dos pais ou de alguém que exerça a função paterna, de autoridade e de instituição de normativas e limites para a vida social, estes fatores podem contribuir para o desencadeamento do perfil antissocial juvenil, os quais tendem ficar completamente desprovidos de estrutura e recursos para aprenderem e evoluir como pessoas. ${ }^{(1)}$

A falta dessa presença/função paterna acarreta sequelas e sofrimentos em toda a estrutura familiar e sobre o próprio jovem, pois devido à ausência de autoridade e de alguém que faça o papel das interdições este fica vulnerável a vários fatores de risco; como, a tendência ao comportamento transgressor - agressivo - hostil - deprimido - antissocial. Muitos pais não conseguem cumprir com esse papel de autoridade, escolhendo como de educar medidas mais punitivas e repressoras, e que não surte efeito positivo para o desenvolvimento desse adolescente; pois em toda essa trajetória familiar a mãe que era para ser um modelo de cuidadora - capaz de oportunizar acolhimento e segurança, passa a se sobre carregar com a falta desse pai. ${ }^{(1)}$

Pode - se dizer de que a falta de um responsável que fizesse o papel das instituições das regras e limites e da lei em sua formação, se coaduna com a realidade de muitos jovens que ousam desafiar as normas sociais e autoridade; bem como, se não tiveram amor - segurança e proteção por parte de seus cuidadores, esses atos de infração podem estar relacionados à procura desse pai autoridade - a lei simbólica.

Outubro, 2016:2(Edição Especial):117-137 
Baseado em relatos de adolescentes que cumprem medidas sócias educativas, um estudo relata que adolescentes que praticam atos infracional, tem origem de toda problemática os mesmos problemas familiar, são filhos de pais separados, e que foram de alguma forma maltratados, e que sofreram algum tipo de violência por parte de seus cuidadores, cuidadores esses que são usuários de drogas ilícitas - envolvidos com atos que agridem a sociedade e que chegam a ser presos; bem como, pais que arrumam outro parceiro e passam a ter uma convivência de muitas brigas e agressões tanto física quanto verbal, um ambiente com muito conflitivo que acaba trazendo danos à - esses adolescentes que em muitas vezes sai de casa e passa a morar com colegas, colegas esses que tem conflito com a lei e passa a ser referência ou modelo de comportamento para esse adolescente, que para o desenvolvimento psicológico desse jovem e negativo. ${ }^{(2)}$

Os adolescentes acabam abandonando a escola quase que na mesma série entre a quarta e a quinta série, e começam a praticar atos transgressores, como, roubo à mão armada, violação a patrimônio público, uso de entorpecentes; como o craque, maconha e outros tipos de droga.Toda essa problemática e desenvolvimento antissocial foi evidenciada, em relatos feitos por adolescentes que cumprem medidas sócias educativas. ${ }^{(2)}$

O objetivo proposto para este trabalho foi analisar o papel do psicólogo nas medidas socioeducativas aplicadas as adolescentes em conflito com a lei. A importância do tema se deve ao aumento de atos infracionais cometidos por adolescentes e a necessidade de se ampliar o estudo sobre a participação da psicologia diante dessa realidade.

Para sua realização optou-se pela pesquisa bibliográfica e webliográfica com a utilização de livros, artigos, monografias, dissertações e teses conseguidos por meio de empréstimos em bibliotecas e buscas em dados da internet tais como SCIELO, LILACS, PEPSIC, e sites de instituições de Ensino Superior dentre outros. As palavras chave utilizadas para a busca dos materiais foram: ato infracional, adolescente, medida socioeducativa e psicólogo. Foram utilizadas obras publicadas no idioma português no período de 1998 a 2015.

O trabalho está estruturado em três seções, sendo a primeira um estudo sobre a adolescência e sobre o adolescente infrator. Na segunda seção, a investigação se fundamenta no estudo sobre os fatores de risco e proteção e a terceira seção aborda a atuação do psicólogo em programas de medida socioeducativa.

O presente estudo será de grande valia para a sociedade acadêmica, por se tratar de um tema atual e em discussão, levantando informações e produzindo diagnósticos que poderão enriquecer a literatura existente, bem como servir de subsídio a novos projetos a serem desenvolvidos nesta área.

Outubro, 2016:2(Edição Especial):117-137 


\section{A ADOLESCENCIA E OS ADOLESCENTES INFRATORES}

A fase da adolescência é uma fase de transição entre a infância e a vida adulta, período esse de grandes transformações biológicas, psicológicas, e sociocultural, sendo os primeiros indícios físicos da maturidade sexual com o término na realização social de adulto independente. ${ }^{(3)}$

A adolescência é a etapa da vida em que o ser humano deixa de ser criança, e abandona suas atitudes infantis e passa pelo processo característico de entrada para a vida adulta. Destacando as perdas vividas na adolescência em que deixa seu corpo infantil e adquire um corpo adulto mais maduro. ${ }^{(4)}$

A adolescência gera sentimentos contraditórios, relata ainda que esta fase de transição inclui ideias megalomaníacas onde o indivíduo se sente superior aos outros dando entender que tem o poder de mudar o mundo. ${ }^{(5)}$

Estudos revelam que o indivíduo deveria construir sua personalidade durante a adolescência, mas que é uma construção que ocorre em indivíduos de formas diferentes, pois nesse período ocorrem as construções da infância. ${ }^{(3)}$ Não se pode deixar de considerar o desenvolvimento biológico e emocional do adolescente, para apontar o começo da vida adulta onde o mesmo passa a ser responsabilizado pelos seus atos. ${ }^{(5)}$

A etapa da vida onde estrutura a personalidade está em fase final de estruturação, é a sexualidade que se insere.(4)

A família é a maior influência para o desenvolvimento de habilidades e comportamentos. Para os adolescentes infratores a família é uma grande referência afetiva. (7) Esses jovens são peremptórios, percebendo em seu meio familiar à violência, o uso de drogas licita e ilícitas, separação de seus cuidadores a privação de todas as ordens em seu meio social podendo desencadear comportamentos que infringem a lei. (2)

Estudos relatam que em um contexto escolar, os alunos indisciplinados e agressivos são de família que possuem problemas, e não conseguem educar o mesmo de forma adequada, mas ressalta que não pode generalizar que a família seja influência para tais atos, necessitando mais estudos e pesquisa para apontar tais fatores. ${ }^{(8)}$

O seio em que esse jovem está inserido é responsável pelo desenvolvimento positivo desse adolescente, pois quando os mesmo não cumprem com esse papel de tal maneira, pode provocar graves consequências no desenvolvimento biopsicossocial do adolescente ou criança. ${ }^{(9)}$ Cada membro familiar tem um papel importante para a definição Outubro, 2016:2(Edição Especial):117-137 
social que reproduz a organização funcional desse jovem, sendo assim os mesmos o primeiro sistema de interação do indivíduo. ${ }^{(10)}$

O Estatuto da Criança e do Adolescente (ECA) define que a adolescência é entendia entre doze e dezoito anos, que são períodos de mudanças físicas, cognitivas e psicossociais, período esse de mais intensidade no ciclo vital desse cidadão em pleno desenvolvimento. ${ }^{(11)}$

Além das transformações corporal e fisiológica a transformação psicológica é muito especial, e é nessa fase que há uma busca de identidade individual, grupal e social, e ainda a procura de aceitação e reconhecimento no meio onde vivem. ${ }^{(12)}$ Reforça que essa etapa é marcada por grandes confusões de papeis, dificuldade para estabelecer sua identidade que é uma transferência da infância para a vida adulta sendo nessa faze a definição para a formação de identidade, por isso a importância de variáveis papeis para que o adolescente conheça e escolha quais desempenhará. (3)

A adolescência normal pode ser descrita por uma série de condutas que são classificadas como Síndrome da Adolescência Normal. Pode-se destacar: a busca de si mesmo e da identidade, pelo qual o próprio Erikson afirma que a principal tarefa do adolescente é a busca da identidade adulta; procurar identificar se com um grupo de faixa etária de mesma idade; necessidade de intelectualizar e fantasiar, onde esse jovem procura compensar suas perdas infantis com atividades infantis conscientes, as chamadas crises religiosas, ateísmo absoluto e ou misticismos fervorosos. Outro aspecto a ser destacado é a deslocalização temporal que leva esse jovem a desencadear angustias por temer sua perda infantil. ${ }^{(13)}$

Percebe-se que a evolução sexual do adolescente se manifesta em atividade vivida com culpa pelo fato do exercício da genitalidade. Apresenta ainda, atitudes sociais reivindicatórias que também são conflitos emocionais, contradições manifestos da conduta, gostos e desejos imprevisível. Outro aspecto a destacar é a separação gradativa dos pais que auxilia na identidade, subjetividade do adolescente, e que seus comportamentos apresentam constantes flutuações de humor e do estado de ânimo, expressados na atividade corporal e lúdica. ${ }^{(13)}$

O quadro 1, menciona alguns sintomas que pode ter ou não um desenvolvimento favorável. 
Quadro1- Sintomas e possíveis evoluções favoráveis e desfavoráveis.

\begin{tabular}{|c|c|}
\hline $\begin{array}{l}\text { POSSIVEIS EVOLUÇOES } \\
\text { FAVORAVEIS }\end{array}$ & $\begin{array}{l}\text { EVOLUÇÃO QUE PODE SER } \\
\text { DESFAVORAVEL }\end{array}$ \\
\hline $\begin{array}{l}\text { Contato afetivo saudável com grupo } \\
\text { familiar. }\end{array}$ & $\begin{array}{l}\text { Frieza ou indiferença afetiva com grupo } \\
\text { familiar. }\end{array}$ \\
\hline $\begin{array}{l}\text { Ausência de antecedentes infantis de } \\
\text { agressividade. }\end{array}$ & $\begin{array}{l}\text { Presença de antecedentes infantis de } \\
\text { agressividade impulsiva. }\end{array}$ \\
\hline Ingestão esporádica de drogas. & Ingestão sistemática de drogas em escala. \\
\hline $\begin{array}{l}\text { Pratica de esportes ou hobbies e interesse } \\
\text { artístico-cultural. }\end{array}$ & $\begin{array}{l}\text { Área de lazer circunscrita à prática de nítido } \\
\text { sentido auto heterodestrutivo. }\end{array}$ \\
\hline $\begin{array}{l}\text { Desejo manifesto ou latente de busca } \\
\text { psicoterapêutica. }\end{array}$ & $\begin{array}{l}\text { Ausência de qualquer motivação para } \\
\text { submeter-se à psicoterapia. }\end{array}$ \\
\hline $\begin{array}{l}\text { Presença de níveis significativos de } \\
\text { ansiedade e evidencia de certo grau de } \\
\text { consciência da inadequação do seu } \\
\text { comportamento. }\end{array}$ & $\begin{array}{l}\text { Ausência de ansiedade evidente e nenhum } \\
\text { grau de consciência da inadequação de sua } \\
\text { conduta. }\end{array}$ \\
\hline
\end{tabular}

O quadro 1 mostra que alguns fatores podem influenciar na vida social do adolescente promovendo um desenvolvimento favorável ou desfavorável. Frequentar ambientes com práticas esportivas com uma boa estrutura e acompanhamento profissional é saudável para o desenvolvimento desses jovens. A consciência da inadequação do seu comportamento é importante e é saudável para esse jovem, já quando o mesmo não tem essa consciência estará propenso a cometer atos com mais intensidade. O consumo esporádico de drogas é menos prejudicial, do que quando esse perde o controle de tal consumo sendo um risco para si mesmo e para outros a sua volta. A família ao negar afeto e ter compromisso com o adolescente em pleno desenvolvimento estaria praticamente submetendo esses jovens a ter desenvolvimento desfavorável, mas ao fazer as intervenções necessárias sem agressão 
física e verbal, passa a favorecer um crescimento saudável, sendo que o contato estreito intrafamiliar é um fator importante para o desenvolvimento desses jovens.

Existem três níveis para a formação de adolescentes que cometem atos infracionais, o nível estrutural, o sócio psicológico e o individual.(15)

O nível estrutural são as influências das organizações sociais para a construção do adolescente que comete atos infracionais. Considerando nesse nível a associação entre pobreza, desigualdade sociais ao delinquente, ou seja, o jovem infrator a uma classe de baixa renda.

O nível sócio psicológico são as instituições como família e escola que dependendo da forma como acontecem às relações vão influenciar na autoestima do adolescente, e essa influência de um grupo pode gerar o comportamento desse adolescente infrator. Considera então esse comportamento um resultado negativo na socialização desse jovem com a família a escola e outros que são representantes de normas sociais. Outro aspecto que pode ser considerado nesse nível é a outra baixa estima. A socialização desse jovem em grupos também e considerada uma influência sobre esse adolescente. Fatores esse que influencia esse comportamento de delinquência que está ligado ao nível sócio psicológico.

Por último, o nível individual que corresponde aos aspectos psicológicos e biológicos. Nível esse que são influência de aspectos biológicos hereditários que é da personalidade, como a inteligência que pode ser um fator para a criminalidade. Considerando também para o acometimento a ser considerado isso como influência de um meio é a genética individual do adolescente. Impulsividade, fracasso social de lidar com o outro e de aprender com sua experiência, ausência de se sentir culpado ou não ter remorso pelos seus atos cometido e a falta de ver a dor do e outro e um fator que pode ser considerado como delinquência.

Não é bom que se utilize expressões como menor infrator ou adolescentes infratores, pois essas classificações são consideradas fortes conotações ideológicas, visto que esses jovens estão em fase de desenvolvimento. ${ }^{(16)}$

O estatuto da Criança e do Adolescente denomina esse jovem infrator como delinquente juvenil, evitando assim, a rotulá-los como menor infrator. ${ }^{(11)} \mathrm{A}$ delinquência juvenil é uma síndrome, uma fase do jovem que está relativamente estável e que é um período de desenvolvimento do mesmo. ${ }^{(17)}$ 
Esse termo delinquência reduz a identidade do ato infracional cometido e que o termo e utilizado em textos cientifico facilitando outros estudos e divulgação do trabalho, sendo útil para produção de conhecimento.(18)

Adolescentes vulneráveis são os de classes marcadas pela pobreza e se encontram expostos com mais influência ao meio social em que vive, então é importante a inclusão desses adolescentes em programas sociais, tais como esporte arte e outros sendo mais importante do que somente ser incluído na escola. ${ }^{(19)}$

Diante do exposto, torna-se necessário discutir sobre os fatores de risco e proteção, tendo como objetivo trabalhar a demanda desses adolescentes de forma adequada para que os mesmos não voltem a praticar atos que transgrede a lei, e que possam ter uma recuperação positiva, de maneira que esses jovens tenham uma boa socialização, podendo assim conviver dignamente no meio em que está inserido.

\section{FATORES DE RISCO E PROTEÇÃO EM COMPORTAMENTO DE}

\section{RISCO}

A adolescência é uma ocasião crucial no período vital para o princípio do uso de drogas, seja como simples experiência seja como consumo acidental, impróprio ou abusivo. Problemas enfrentados na adolescência, plantados na infância, têm um contexto de realização muito mais ampliado na vida do jovem construindo espaços fundamentais de risco e de proteção.

\subsection{FATORES DE RISCO}

Risco é uma decorrência da livre e consciente deliberação de se expor a uma ocasião na qual se procura a efetivação de um benefício ou de um anseio, em cujo decurso se abrange a probabilidade de prejuízo ou lesão física, material ou psicológica.

O indivíduo que tem a virtude fundamental da fortaleza expõe-se ao risco da morte por um bem. $\mathrm{O}$ autor expõe ainda que existem três condições para a significação de risco: (1) probabilidade de existir perda; (2) possibilidade de lucro; e (3) possibilidade de acrescentar ou de diminuir o prejuízo ou os estragos. ${ }^{(20)}$ 
Como explica Heidegger, o risco é intrínseco à vida, e à probabilidade de opção. Viver é estar sempre correndo risco e por isso a dúvida é um elemento fundamental da vida e do mesmo modo faz parte conceito de risco. (21)

Existe uma separação importante entre o conceito risco e perigo. Explica-se que os dois vocábulos não são unívocos, porém sua acepção se aproxima. Perigo se refere a iminências que aceiram a procura dos frutos almejados. Constitui uma avaliação a respeito do perigo. No que se refere à saúde, risco abrange informação e conhecimento a respeito do perigo de alguma pessoa ou dá a sociedade ser assaltada por doenças e insultos. Neste caso o vocábulo principal da epidemiologia, alude a circunstâncias concretos ou possíveis que determinam resultados diversos e conformam cuidados. A expressão aplicada fatores de risco indica situações que denotam a probabilidade de acontecimentos de efeitos contraproducentes para a saúde, e o bom desempenho social. (20).

Certos números desses fatores se fazem referência as peculiares dos sujeitos; outros, ao meio em que vivem e outros, ainda, a situações relacionadas a vivencia e social e cultura mais amplas, mas, comumente, estão ajustados quando uma situação considerada social, ameaçadora se consolida. (22)

A juventude é uma fase da vida em que aparecem as grandes preocupações no que se refere ao consumo de drogas, uma vez que os anos adolescentes representam uma ocasião de exposição e vulnerabilidade. Assim, a ingestão de álcool, o uso de cigarro e outras drogas pelos genitores, a ausência de compromisso para com as atividades escolares, desestrutura familiar, agressão doméstica e a pressão de grupos, entre outros fatores, são agravantes que podem levar ao consumo de drogas e têm sido foco de estudos. ${ }^{(23)}$

Muitos outros motivos que levam o jovem ao consumo de drogas são muito análogos àqueles que fazem parte da juventude como os conflitos psicossociais, a precisão de se integrar ao social, a procura da autoestima e de independência da família. A prática de consumir de drogas é um acontecimento complicado, com procedência e implicações do tipo biológico, psicológico e social. Afirma ainda que pode ser em decorrência de conflitos ou desestrutura familiar, tal episódio aponta a falha na coordenação da família e sugere necessidade de transformações no seu procedimento com o jovem. ${ }^{(24)}$

A literatura aponta que, no processo de adoecimento do dependente químico, um dos fatores, mas não o único, que o motiva ao uso de drogas e às possíveis recaídas tem relação com a inabilidade da família em lidar com o comportamento de seu familiar dependente, necessitando também ela de acolhimento e acompanhamento. Os integrantes da família enfrentam situações de angústia, conflitos, dúvidas, medos e outros sentimentos Outubro, 2016:2(Edição Especial):117-137 
durante a terapêutica do seu ente ou entes adoecidos, portanto requerem um espaço terapêutico para serem ouvidos e ajudados.

A carência de afinidades afetuosas puras e de contribuição familiar, a influência do grupo, a agressão doméstica, antecedentes familiares dependentes químicos e baixa autoestima têm sido referidas como fatores de precipitação para uso e dependência de substâncias. ${ }^{(25)}$

As probabilidades de fatores genéticos abarcados nos aspectos de dependência química, são de grande valor na atualidade, uma vez que averiguações de genes que constituem uma informação genética têm assinalado características para o caso de funções neurobiológicas tornarem o indivíduo predisposto ao uso de ocasionais substâncias químicas. Todavia não há uma forma de antever se o indivíduo será um usuário inicial ou se tornará um dependente, este procedimento posterior vai estar sujeito às condições psicológicas e sociais do sujeito. ${ }^{(25)}$

Geralmente, jovem que ingere droga inicialmente o faz procurando prazer e não dor e sofrimento. Está procurando prazer, novas impressões, inserir no grupo, ser diferente, liberdade e bem-estar em relação à família, em meio a outros resultados. E nessa procura não imagina o perigo a que se expõe. (26)

O caminho contraproducente, segundo o autor citado anteriormente, que pode levar o desejo juvenil de alcançar prazer utilizando de drogas é o risco de ficar submisso e afetar a efetivação de afazeres naturais do desenvolvimento; o convívio social esperado; a obtenção de aptidões fundamentais; a efetivação de um significado de adaptação e capacidade e a preparação adequada para a mudança na direção da vida: o adulto jovem.

A expressão comportamento de risco, portanto, se faz alusão as iminências negativas ao desenvolvimento bem-sucedido do adolescente. Por isso, de acordo com Bloise, quanto maior o habito do uso de drogas, mais fatores de risco há. Essa comprovação contraria a opinião de que existiria uma continuação na seriedade do risco, indo do envolvimento contínuo com drogas mais leves para um crescimento na direção das mais perniciosas. Alguns estudos comenta o autor, chegam a aludir que cigarro e álcool funcionariam como ponte para uma trajetória crescente de implicação com drogas cada vez mais pesadas. ${ }^{(22)}$

Expõe que muito se tem ponderado em relação ao papel da escola seja como influente transformador, seja como lugar que aguça as situações para o uso de drogas. Nenhuma pessoa ignora que a escola é hoje alvo do assédio de traficantes e repassadores de drogas, havendo ali aliciamento por pares. Pois a escola é o lugar privilegiado dos Outubro, 2016:2(Edição Especial):117-137 
encontros e intercâmbios entre jovens. Entretanto, mesmo no recinto educativo, existem fatores peculiares que predispõem os jovens ao uso de drogas, como por exemplo, a falta de incentivo para os estudos, o desempenho escolar insuficiente; o desejo de ser livre conjugado com o empenho de buscar a efetivação do crescimento pessoal, a procura de inovação a qualquer custo e o espírito de aventura; a rebeldia te anexa à dependência a gratificações.

Os múltiplos elementos versados acima levam a concluir que não se podem refletir os fatores de risco de modo isolado e fragmentado. Um fator de risco dificilmente é peculiar de um distúrbio exclusivo, porque seus argumentos formadores têm a tendência de disseminar as consequências originárias de seus efeitos sobre uma série de funções ao longo do desenvolvimento. E a exposição ao perigo tornam maiores os riscos de diferentes formas e em múltiplos contextos. ${ }^{(23)}$

\subsection{FATORES DE PROTEÇÃO}

Proteger é uma noção que faz parte do contexto das relações primárias, significando dar condições de crescimento e apoio à pessoa que está em processo de formação. ${ }^{(27)}$ É conceituado como sendo os recursos particulares ou sociais que diminuem ou paralisam o conflito do risco. ${ }^{(28)}$

Outra forma de conceituá-lo é como fatores protetores os que contrapesam as vulnerabilidades para os procedimentos que induzem ao uso ou abuso de drogas. ${ }^{(29)}$

No combate àdroga dicção, a prevenção é assinalada como um dos conceitos complementares na elevação de saúde. A visão de prevenção valoriza a utilização da educação não simplesmente como um amontoamento de conhecimentos sobre drogas, mas a educação operando como um procedimento sucessivo de edificação da aprendizagem, voltado à ampliação de capacidades psicossociais que permitam ao sujeito um desenvolvimento social e afetuoso equilibrado. (30)

Os programas de prevenção e interferência precoce têm mais baixo custo do que programas essenciais de terapêutica. Assim, deve ser ressaltada a necessidade do aperfeiçoamento dos programas de prevenção, focalizando, não somente os motivos que induziram determinados adolescentes a conhecer drogas, que consentiu que outros se recusassem.

A sociedade tem uma função essencial na proteção de crianças, adolescentes e jovens contra o envolvimento com substâncias químicas e outros procedimentos de risco. As ações sugeridas para alargar os fatores de proteção devem empregar os expedientes Outubro, 2016:2(Edição Especial):117-137 
disponíveis na sociedade, considerando as peculiaridades socioculturais de suas referentes conjunturas e acionando a rede de contribuição. Ao mesmo tempo, apresentadas as particularidades locais, todas as ações devem ser dirigidas pelo princípio da capacidade criadora e do aproveitamento da potencialidade inovadora, tanto dos jovens quanto das diferentes esferas comunitárias. ${ }^{(31)}$

A convivência no seio familiar é um grande fator de proteção para esses adolescentes, jovens que convivem em ambientes conflitantes e que de alguma forma foi agredido física, emocional e socialmente quando criança tem mais facilidade de fazer o uso de drogas desenvolvendo comportamentos agressivos. A família como tem função essencial e a maior contribuição familiar de proteção em analogia ao uso de drogas e outros procedimentos de riscos é o vínculo de afinidade entre os pais e os filhos. A negligência parental favorece uma conduta antissocial do adolescente, contribuindo para que o mesmo passe a participar de grupos que já estão envolvidos no crime, sendo uma pratica. ${ }^{(32)}$

A sociedade considerada como agente de fatores protetores e a escola como uma das mais respeitáveis instituições, , pois o jovem ao se sentir componente da comunidade escolar, ao se sentir estimado e conseguir sucesso na história acadêmica, se sentirá mais resguardado contra os fatores de risco.

Professores, diretores, acadêmicos e comunidade devem batalhar para existirem nas escolas de ensino básico e superior 'espaços saudáveis', livres de drogas. Destaca também que é importante a crença religiosa, socialização com amigos, escola, são fatores que fornecem suporte emocional, e apresenta que os professores podem ser um modelo positivo para identificação de uma criança em risco. ${ }^{(26)}$

Igualmente as Instituições Religiosas são distinguidas como fatores de proteção contra os procedimentos de risco, especialmente aos jovens que conservam práticas religiosas.Sujeitos que nas ocasiões de lazer buscam botecos, festejos e boates têm 73,3\% mais oportunidades de cometer práticas ilícitas do que os outros que praticam atividades esportivas, culturais e religiosas. ${ }^{(33)}$

Vínculo com avôs ou irmãos são fatores protetores, que os mesmos se tornam suporte importante em momentos estressores, influenciando competência, autonomia e confiança da criança. ${ }^{(34)} \mathrm{O}$ temperamento positivo, habilidades acima da média, competência em atividades, facilidade em se socializar, autoestima, fatores familiar favorável, suporte dos pais e relacionamento estreito familiar é um grande fator de proteção. Outros fatores que podem ser positivo são relacionamentos com pares, ou seja, fora da família, adultos que sejam 
exemplos para sua construção social que não tenha comportamentos negativos, manter contato com instituições que promova atividades saudáveis. ${ }^{(35)}$

Os mesmos autores mencionam que os fatores protetores podem ser designados ou delineados como fatores de proteção de condutas 'saudáveis' de um sujeito ou de um determinado grupo social particular, deste modo, o estudo precedente de um determinado grupo para se avaliarem quais os seus fatores protetores é muito importante para a eficácia na preparação e efetivação de ações opostas ao uso abusivo de drogas.

Baseado em relatos de adolescentes que cumprem medidas sócias educativas pesquisadores citam que adolescentes que praticam atos infracional, tem origem de toda problemática nos mesmos problemas familiar, que são: filhos de pais separados, e que foram de alguma forma maltratados, e que sofreram algum tipo de violência por parte de seus cuidadores, cuidadores esses que são usuários de drogas ilícitas - envolvidos com atos que agridem a sociedade e que chegam a ser presos; bem como, pais que arrumam outro parceiro e passam a ter uma convivência de muitas brigas e agressões tanto física quanto verbal, um ambiente com muito conflitivo que acaba trazendo danos à - esses adolescentes que em muitas vezes sai de casa e passa a morar com colegas, colegas esses que tem conflito com a lei e passa a ser referência ou modelo de comportamento para esse adolescente, que para o desenvolvimento psicológico desse jovem e negativo. ${ }^{(2)}$

Esses adolescentes acabam abandonando a escola quase que na mesma série entre a quarta e a quinta série, e começam a praticar atos transgressores, como, roubo à mão armada, violação a patrimônio público, uso de entorpecentes; como o craque, maconha e outros tipos de droga. Toda essa problemática e desenvolvimento antissocial foi evidenciada, em relatos feitos por adolescentes que cumprem medidas sócias educativas. ${ }^{(2)}$

A Associação Americana de Psicologia (APA) aponta alguns fatores que contribuem para proteção desses adolescentes mesmo quando os mesmos vivendo em situações de risco, destacando assim a resiliência. Fatores relacionados à resiliência: relacionamento com um adulto que seja significativo para esse jovem sendo parental ou não pratica religioso ou espiritual, influenciar aos estudos dando suportes adequados, ambiente familiar sem riscos de negativo colocando limites, respeito pala autonomia do jovem entre outros, inteligência emocional e facilidade para lidar com estresses. ${ }^{(36)}$

Programa de habilidades familiares, terapia breve e programas de prevenção e de proteção às adolescentes que estão expostos a fatores de riscos são métodos eficaz para reduzir problemas em adolescentes, facilidade na comunicação efetiva de expectativa, valores Outubro, 2016:2(Edição Especial):117-137 
familiares e promover um tempo que os familiares passem mais tempo juntos reduz a influência inadequada dos pares evitando assim que o adolescente se envolva como atitudes ante social. (37).

\section{A ATUAÇÃO DO PSICÓlOGO EM PROGRAMAS DE MEDIDA SOCIOEDUCATIVA}

A realidade brasileira mostra um fator a ser considerado: a pouca literatura que possa avaliar o psicossocial desse jovem com o intuito de ajudar na decisão do judiciário, material esse que possa contribuir no desenvolvimento de estratégias de atendimento adolescente infrator. ${ }^{(11)}$

Diante do estudo sobre as medidas socioeducativas, o CFP (2010) destaca duas medidas: sendo uma a meio aberto e outro de privação de liberdade. A medida sócia educativa de meio aberto, ou seja, liberdade assistida implica prestação de serviço à comunidade, que seria priorizada. (Já a medida de privacidade: o adolescente é recolhido sem direito a saídas, sendo esse privado de liberdade se o ato for grave, e tendo apenas visitas semanais). Essa medida seria em último caso, no intuito de responsabilizar o adolescente pelo ato infracional cometido.

A medida Liberdade Assistida Comunitária (LAC), que seria um processo educativo comunitário, que cria condições favoráveis para que o adolescente possa ser novamente inserido a sociedade tendo direito de liberdade, esse trabalha é realizado através de Educadores Sociais onde os mesmo são voluntários credenciados pelo Juiz da Infância e da Juventude, possibilitando o menor infrator a uma reinserção social, no entanto os educadores sociais e profissionais que atuam com o adolescente deverão manter contato com a escola, família, incentivando-o em programas profissionalizantes e seguidos de demais ações que seja necessária para à reinserção social do adolescente. ${ }^{(38)}$

A autora pontua ainda que a Orientação Social realizada pelo Educador Social, pela equipe multidisciplinar, da qual faz parte o psicólogo, deverá trabalhar as dificuldades do adolescente estabelecendo elos entre educador, adolescente, a família, o Juiz e o Ministério Público, realizando reuniões periódicas de estudos de caso, fazendo avaliações, desenvolvendo atividades de formação, enviando relatórios de acompanhamento às autoridades competentes. 
O Sistema Nacional de Atendimento Socioeducativo (SINASE), foi constituído em uma política pública com o intuito de interagir com os sistemas estaduais, municipais, distritais e municipais para contribuírem nos meios de educação, trabalho, saúde, assistência social, previdência social, cultura, esporte, lazer, segurança públicas entre outras, e que possa integrar o adolescente infrator com a lei, criando também o Plano Individual de Atendimento(PIA), que é um formulário preenchido pela equipe multidisciplinar contendo dados pessoais do adolescente inscritos no programa de trabalho com esse jovem de maneira individual, sendo cada caso tratado de maneira particular sobre cada demanda e contextos que o infrator está inserido. Esse plano é uma ferramenta de muita importância para a evolução pessoal e social do adolescente, fazendo com que esse possa conquistar suas metas e compromissos proposto na adequação das necessidades do adolescente e sua família, sendo essa ó ponto principal da execução das medidas socioeducativas. ${ }^{(39)}$

O profissional da psicologia atua nas medidas socioeducativa, desenvolvendo práticas que contribuem para a produção de políticas públicas que unem Estado, família e sociedade, tendo como objetivo pesquisar e diagnosticar junto aos profissionais que trabalham na área de medidas socioeducativas, a responsabilidade e compromissos éticos com o futuro e o presente de novas gerações. ${ }^{40}$

A psicologia em seu contexto jurídico traz um papel muito importante, avaliar, tratar e desenvolver atividades psicoterapêuticas, estudar e analisar as intervenções possíveis para serem aplicadas nos sistemas prisionais em geral, outras solicitações como: laudos, participações em reuniões como Comissão Técnicas de Classificação (CTC), que elabora programas individuais para Tratamentos do adolescente, discussão de casos que se baseia em uma proposta de individualização, assim também como as reuniões semanais do Conselho Disciplinar (CD), a autora destaca que o tratamento de adolescentes em medida socioeducativa seria orientando pelo princípio de humanização das relações sobe amparo dos Direitos Humanos, nas reuniões de CTC é analisado de alguma foram o histórico pessoal de cada infrator, sendo levantado dados que o leva acometer tais atos, como, a família, o histórico do crime e seus comportamentos, para melhor encaminhamento a uma intervenção que esteja disponível e necessária. ${ }^{(41)}$

Quanto ao trabalho do psicólogo em unidades de privação de liberdade o trabalho seria desenvolvido no intuito de produzir intervenções através de compromissos ético-político para garantir ao adolescente direitos, recorrendo na ECA e nas normas internacionais, sendo que a pratica desenvolvida integra outros membros que passam a fazer parte do contexto interdisciplinar da equipe técnica, desenvolvendo e construindo conhecimentos e respeitando 
o Código de Ética, evitando superioridade nos membros da equipe multiprofissional, objetiva em elaborar relatórios e pareceres técnico conforme resolução CFP n 07/2003 (produzir documentos qualificados decorrentes de avaliação psicológicas, frequência com que representa a ética desencadeada a partir de queixas que colocam em questão a qualidade dos documentos entre outros), na tentativa de não rotular e considera as condições que existe para o cumprimento da MSE (medida sócio educativa). ${ }^{(40)}$

As autoras relatam ainda que, o trabalho do psicólogo não se restringe apenas na elaboração de pareceres e relatórios, mas deverá contribuir para garantir e atribuir no planejamento da instituição e organização e implantação das rotinas institucional.

O psicólogo tem as seguintes atuações: analise de situação no intuito de diagnosticar a realidade através de pesquisas que facilita o planejamento de ações e recursos para ancorar de frente situações de risco, mobilizando vários segmentos como, governamentais, sociedades civis nos níveis nacionais, regionais e locais, desenvolvendo promoção, responsabilização e defesa às traves de mecanismos dos direitos e humanização dos serviços, promovendo atendimento, prevenção sobre ações especializadas de atendimentos, incluindo socialmente a criança e ao adolescente, ou seja, inclusão social da mesma e sua família em promoções e ações que da possibilidade aos jovens emponderamento dos adolescentes com visitas ao protagonismo social, o objeto de intervenção do psicólogo passa a atingir aspectos da vida no concreto, cotidiana e seus efeitos de subjetividade, que reproduz e realimenta no entrelaçamento dos indivíduos entre si e com a entidade. ${ }^{(42)} \mathrm{O}$ Ministério do Desenvolvimento Social destaca que o psicólogo tem como trabalho no sistema, garantir juntamente com outros profissionais, ser um viabilizador de direitos, tendo conhecimento da legislação exigindo novas competências, e autonomia de políticas administrativa que propõem a participação nas relações entre gestores, técnico governamentais, prestadores de serviços técnicos e dirigentes, conselheiros e os usuários que visa o fortalecimento de práticas e espaços de debate. ${ }^{(43)}$

No desenvolvimento de seu trabalho junto aos adolescentes o psicólogo desenvolve grupos psicoterapêuticos com a abordagem de uma temática em cada encontro que possa envolver os amigos, a sociedade e família, pontuando que esse adolescente tem direito e deveres; produzindo reflexão sobre seu futuro e expectativas de trabalho, no entanto esses grupos são limitados esse trabalho traz o resgate da memória, álbuns de família que são dados importantes para reorganização de sua história no objetivo de fazê-lo pensar na sua identificação e na sua identidade. ${ }^{(41)}$ 
O psicólogo não pode deixar de considerar cada situação em privação de liberdade do adolescente, nas unidades de internação, no cumprimento de medida socioeducativa ou até mesmo em unidade de internação provisória, período esse que não pode exceder quarenta e cinco dias ou três anos, reconhecer e respeitar a existência de normas nacionais - ECA, serem cooperativo em trabalho com equipe multiprofissional dominar habilidades e ter dialoga com outras especialidades do conhecimento de diversas áreas profissionais. ${ }^{(44)}$

Um trabalho importante para o profissional da psicologia é de amenizar os efeitos que o ambiente possa causar no interno, local punitivo que é a instituição. ${ }^{(45)}$

O profissional psicólogo pode ser ainda uma referência para seu cliente, pois o ambiente da instituição de internamento onde o mesmo se encontra, possui regras e normas, sendo assim o psicólogo terapeuta sua expressão de liberdade onde se encontra com pouca interação entre os outros internos. ${ }^{(45)}$

Diante disso, pode-se perceber que é importante que o psicólogo no desenvolvimento de seu trabalho, faça com que o adolescente desperte a visão não apenas da própria realidade, mas da realidade social na qual está inserido, fazendo com que percebam suas relações interpessoais para assim aprender processos de construção enquanto um ser social e se organizando pessoalmente, desenvolvendo sua capacidade pessoal para um bom convívio social e individual, com objetivo de ter uma mudança, e reverter à visão da sociedade de que são infratores e sua própria visão de si mesmo.

\section{CONCLUSÃO}

A fase da adolescência é uma um período entre a infância e a vida adulta, período de grandes transformações onde abandonam suas atividades infantis e passam por um processo característico de adultos deixando sua adolescência e seu corpo infantil e adquirindo um corpo de adulto mais maduro, período de construção da personalidade que ocorre em indivíduos de formas diferente, sendo essas biológicas, psicológicas e sociais, uma fase que requer muita atenção de seus cuidadores.

Pode-se evidenciar que a falta de afeto e atenção de seus cuidadores pode ter influência para que adolescentes desenvolva comportamentos não aceito pela sociedade e as autoridades, a influência do grupo, a agressão doméstica, antecedentes familiares que fazem uso de produtos químicos e baixa autoestima, a falta de incentivo para os estudos, o Outubro, 2016:2(Edição Especial):117-137 
desempenho escolar insuficiente; o desejo de ser livre conjugada com o empenho de buscar a efetivação do crescimento pessoal, a procura de satisfazer seus desejos de consumo a qualquer custo e o espírito de aventura; a rebeldia tem anexa à dependência a gratificações, têm sido referidas como fatores de risco precipitando o desenvolvimento de comportamentos inadequados, ou seja, antissocial no convívio com a sociedade e que são precárias as explicações sobre os fatores protetores que possam esclarecer os motivos de jovens que fazem parte desse grupo de risco.

A psicologia contribui no desenvolvimento de programas de medidas socioeducativas, intervenções através de compromissos ético-político e garantir ao adolescente direitos juntamente com outros profissionais. Fazer com que o adolescente desperte sua visão não apenas da própria realidade, mas que o mesmo perceba as realidades sociais na qual está inserido, fazendo ó perceber suas relações interpessoais e se organizar pessoalmente, desenvolvendo suas capacidades pessoais para um bom convívio individual e sociais. Criando condições favoráveis para que o adolescente possa ser novamente inserido a sociedade, tendo direito de liberdade.

\section{REFERENCIAS}

1. Dias ACG; Aprini DM, Simon BR. Um Olhar Sobre a Família de Jovens que Cumprem Medidas Socioeducativas. Psicologia e Sociedade: UFSM Universidade Federal de Santa Maria, [Internet]. Santa Maria, RS; s. d. [2015 jun. 04]. http://www.redalyc.org/articulo.oa?id=309326607010

2. Castro ALS, Guareschi, P. Da privação da dignidade social à privação da liberdade individual.. Psicologia Social. 2008;20(2):200-207.

3. Mendes Delza F, Silva Tatiane $C$ da. A contemporaneidade acerca da adolescência e sexualidade. Revista Psicologia e saúde em debate [Internet]. São Paulo; s. d.. [2015 nov. 12]. https://psicodebate.files.wordpress.com/2014/12/1-silva-mendes2015.pdf

4. Azevedo JM. A função paterna nas configurações familiares atuais. [dissertação]. Belo Horizonte: Pontifícia Universidade Católica de Minas Gerais;2008.

5. Lepre RM. Adolescência e construção da identidade. Psicologia online [Internet]. ; s. d. [2015 dez. 12]. http://www.psicopedagogia.com.br/artigos/artigo.asp?entrlD=395

6. Ferreira M, Nelas PB Adolescências...Adolescentes...Millenium on. Line: Revista do Instituto Superior Politécnico de Viseu [Internet]. 2006 [2016 fev. 15];32(4):141-162. http://www.ipv.pt/millenium/Millenium32/11.pdf. 
7. Bolsoni-Silva A T, Marturano EM et.al. Pesquisando a família: instrumentos para coleta e análise de dados . Curitiba: Juruá; 2009. Roteiro de entrevista de Habilidades Sociais Educativas Parentais RE-HSE-P; p. 250-257.

8. Araujo C. A Violência Desce para a Escola: Suas manifestações no Ambiente Escolar e a Construção da Identidade dos Jovens. 2a Belo Horizonte: Autêntica; 2004.

9. Trentin AC. http://ebooks.pucrs.br/edipucrs/anais/cienciascriminais/edicao2/Angela_Trentin.pdf [dissertação mestrado]. Porto Alegre: Faculdade de Direito do Rio Grande do Sul, Porto A;2011.

10. Batista $E$, Oliveira $B$, Pires $S$. A influência da família na aquisição de modelos agressivos pelas crianças.. Psicologado-Artigos de Psicologia [Internet]. São Paulo; s. d. [2016 mar. 30]. http://artigos.psicologado.com/psicologia-geral/desenvolvimentohumano/a-influencia-da-familia-na-aquisicao-de-modelos-agressivos-pelas-criancas

11. Brasil. Estatuto da Criança e do Adolescente, 13 de julho de 1990. Senado Federal, Subsecretaria de Edições Técnicas [Internet]. Brasília; s. d. [2016 abr. 21]. www.gov.br/ccivil/LEIS/L8069.htm

12. Zimerman DE. Fundamentos psicanalíticos: teoria, técnica e clínica. Porto Alegre: Artmed; 1999.

13. Knobel M. A Síndrome da adolescência normal. Porto Alegre: Artes Médicas; 1991.

14. OSÓRIO L C. Adolescente hoje. 3. ed. Porto Alegre: Artmed, 1989.

15. Schoemaker DJ. Theories of Delinquency. An Examination of Explanations of Delinquent Behavior. New York: Oxford University Press; 1996.

16. Volpi M. O adolescente e o ato infracional. São Paulo: Cortez; 1997.

17. Silva DFM. O desenvolvimento das trajetórias do comportamento delinqüente em adolescentes infratores [tese]. Porto Alegre: Universidade Federal do Rio Grande do Sul;2002.

18. Foucault M. Vigiar e Punir. 32ª ed. Petrópolis: Vozes; 1997.

19. Outerial J. Adolescer. $3^{\mathrm{a}}$ ed Rio de Janeiro: Revinter; 2008.

20. Assis SG. Traçando caminhos em uma sociedade violenta. Rio de Janeiro: Fiocruz; 1999.

21. Heidegger M. Abril, São Paulo. (Coleção Os Pensadores) 1980.

22. Bloise PV. O arquétipo do Herói: dependência e desenvolvimento. São Paulo: Atheneu; 2006.

23. Grego Filho V. Tóxicos: prevenção - repressão. 13a São Paulo: Saraiva; 2009. 
24. Silva E. A Abordagens familiares. Jornal Brasileiro de Dependência Química, v. 2, Supl. 1, p. 21-24, 2001.

25. Andretta I, Oliveira M. A entrevista motivacional na adolescência. Revista de Psicologia Clínica. 2005;17(32):127-139.

26. Barreto LM. Dependência Química: nas escolas e nos locais de trabalho. . Rio de Janeiro: Qualytimark; 200.

27. Vizzolto MS. Drogas: respostas para as dúvidas mais freqüentes. São Paulo: Geração Saúde; 2000.

28. Sanchez Z, Oliveira L, Nappo S. Razões para o não uso de drogas ilícitas entre jovens em situação de risco. Revista de Saúde Pública. 2009;39(4):599-605.

29. Zemel, MLS. Prevenção: novas formas de pensar e enfrentar o problema. . $2^{\mathrm{a}}$ ed. Brasília: SENAD; 2010.

30. Duarte CE, Morihisa RS. Experimentação, uso, abuso e dependência de drogas. Texto adaptado do original do Curso Prevenção ao uso indevido de drogas: Capacitação para Conselheiros Municipais, 2008. In: BRASIL. Presidência da República. Secretária Nacional de Políticas sobre drogas - SENAD. Prevenção ao uso indevido de drogas: capacitação para conselheiros e lideranças comunitárias. 2. ed. Brasília, DF, 2010. Unidade 2.

31. Conceição MIG, Oliveira MCS. Prevenção ao uso indevido de drogas: capacitação para conselheiros e lideranças comunitárias. Presidência da República. Secretária Nacional de Políticas sobre drogas. 2010;16(75):259.

32. Silva MTA et.al. Sobre comportamento e cognição. Santo André: USP; 2006. Análise funcional da dependência de drogas; p. 422-442.

33. Bastos FI, Bertoni N, Hacker MA. Consumo de álcool e drogas: principais achados de pesquisa de âmbito nacional, Brasil 2005. Arca: Repositório Institucional da Fiocruz [Internet]. São Paulo; s. d. [2015 abr. 28]. http://www.arca.fiocruz.br/handle/icict/1310

34. Werner EE. Handbook of early childhood intervention. Nova York: Cambridge University Press; 1998. Protective factors and individual resilience; p. 13-20.

35. Rae-Grant et. al. Protective factors, and the prevalence of behavior and emotional disorders in children and adolescents. Journal of American Academy of Child and Adolescent Psychiatry, [Internet]. USA; s. d. [2015 dez. 28]. http://www.ncbi.nlm.nih.gov/pubmed/2925581

36. Rutter M. Resilience in the face of adversity. British Journal of Psychiatry. 1985;147(.):598-611.

37. Kumpfer KL, Alvarado R. Family-strengthening approaches for the prevention of yputh problem behaviors. Am Psychol [Internet]. 2003 [2015 nov. 30];58(6-7):456-65. http://www.ncbi.nlm.nih.gov/pubmed/12971192. 
38. Martins MAPM. Medida Sócio - Educativa de Liberdade Assistida. In: Secretaria de Cidadania e Trabalho. Secretaria de Cidadania e Trabalho Superintendência da Criança, do Adolescente e da Integração do Deficiente [Internet]. Goiània; s. d. [2016 abr. 02].

http://www.mp.go.gov.br/portalweb/hp/8/docs/manual_prestacao_de_servicos_a_co munidade.pdf

39. Brasil Presidência da República. Sistema Nacional de Atendimento Socioeducativo. Secretaria Especial dos Direitos Humanos. Conselho Nacional dos Direitos da Criança e do Adolescente [Internet]. Brasília; s. d. [2016 maio 15].

http://www.condeca.sp.gov.br/legislacao/sinase_integra.pdf

40. Conselho Federal de Psicologia CFP. Referências técnicas para atuação de psicólogos no âmbito das medidas socioeducativas em unidades de internação. Conselho Federal de Psicologia [Internet]. Brasília; s. d. [2016 maio 28]. http://www.ufrgs.br/napead/repositorio/objetos/estacaopsi/anexos/referencias_CRP.pdf

41. Chaves KB. O trabalho do/a psicólogo/a no sistema prisional: o resgate das relações interpessoais no processo De reintegração social também por meio de grupo. Centro de Referência Técnica em Políticas Públicas (CREPOP) Conselho Federal de Psicologia (CFP) [Internet]. Brasília; s. d. [2016 mar. 15].

http://crepop.pol.org.br/novo/wpcontent/uploads/2015/09/CREPOP_PraticasInovadoras_SistemaPrisional_Grupos.pdf

42. Teixeira CL, Novaes EB. Acompanhamento psicossocial de adolescentes: Uma metodologia inovadora no enfrentamento da exploração sexual. . São Paulo: Casa do Psicólogo; 2004.

43. Brasil. Política Nacional de Assistência Social. Ministério do Desenvolvimento Social e Combate à Fome. Secretaria Nacional de Assistência Social [Internet]. Brasília; s. d. [2016 mar. 30]. http://www.sesc.com.br/mesabrasil/doc/Pol\%C3\%ADticaNacional.pdf

44. Teixeira MLT. As histórias de Ana e Ivan: Boas experiências em Liberdade Assistida.. São Paulo: Fundação Abrinq; 2003

45. Rocha GVM. Psicoterapia com infratores de alto-risco: trabalhando a mentira, a vergonha e a culpa. . In: Rovinski SLR, Cruz R M (orgs). Psicologia jurídica: perspectivas teóricas e processos de intervenção. São Paulo: Vetor; 2009. p. 195208. 